\title{
Transcript profiling of sucrose synthase genes involved in sucrose metabolism among four carrot (Daucus carota L.) cultivars reveals distinct patterns
}

Yan-Jun Liu, Guang-Long Wang, Jing Ma, Zhi-Sheng Xu, Feng Wang and Ai-Sheng Xiong ${ }^{*}$

\begin{abstract}
Background: Carrot which contains lots of nutrients has a large demand around the world. The soluble sugar content in fleshy root of carrot directly influences its taste and quality. Sucrose, as an important member of soluble sugar, is the main product of photosynthesis in higher plants and it plays pivotal roles in physiological processes including energy supply, signal transduction, transcriptional regulation, starch and cellulose synthesis, and stress tolerance. Sucrose synthase is a key enzyme involved in sucrose metabolism and is closely related to sucrose content. However, the molecular mechanism involved in sucrose metabolism in carrot has lagged behind.

Results: Here, carrot roots of five developmental stages from four carrot cultivars were collected, and the contents of soluble sugar and sucrose in different stages and cultivars were surveyed. Three DcSus genes (DcSus), DcSus2, and DcSus3), with lengths of 2427 bp, 2454 bp and 2628 bp, respectively, were identified and cloned in carrot. Phylogenetic analysis from the deduced amino acid sequences suggested that three DcSus were clustered into three distinct groups (SUSI, II and III). Results of enzymatic profiles demonstrated that the DcSus activities showed decrease trends during taproot development. Correlation analysis indicated that the DcSus activity showed negative correlation with soluble sugar content and strong negative correlation with sucrose concentration. Quantitative real-time PCR analysis showed that the expression profiles of the DcSus genes are significantly different in carrot tissues (root, leaf blade, and petiole), and the expression levels of the DcSus genes in the leaf blade were much higher than that in the root and petiole. The expression profiles of DcSus genes showed strong negative correlation with both sucrose content and soluble sugar content.
\end{abstract}

Conclusions: During carrot root development, the soluble sugar content and sucrose content showed increasing trends, while DcSus activities had persisting declinations, which may be due to the decreasing expression levels of genes encoding sucrose synthase. Our data demonstrate that synthesis of sucrose in carrot tissue is closely related with DcSus genes. The results from our study would not only provide effective insights of sucrose metabolism in carrot, but also are beneficial for biologists to improve carrot quality.

Keywords: Soluble sugar content, Sucrose synthase, Metabolism, Transcript profiling, Daucus carota L

\footnotetext{
* Correspondence: xiongaisheng@njau.edu.cn

State Key Laboratory of Crop Genetics and Germplasm Enhancement,

College of Horticulture, Nanjing Agricultural University, 1 Weigang, Nanjing

210095, China
} 


\section{Background}

As an important nutrient substance, sucrose plays crucial roles in plant growth and development by transferring from "source" to the "sink" organs in the form of assimilated carbon [1]. Sucrose is an important signal molecule in plants that regulates the expression of microRNA, plant hormone and transcription factor, etc. [2-4]. Sucrose also takes part in the biosynthesis of starch [5-10], cellulose $[11,12]$ and protein. In addition, sucrose participates in plant response to abiotic stresses [13-15].

Previous studies suggested that there are three key enzymes involved in sucrose synthesis and degradation, sucrose-phosphate synthase (EC 2.3.1.14, SPS), sucrose synthase (EC 2.4.1.13, Sus), and invertase (beta-fructofuranosidase, EC 3.2.1.26, Inv). Sucrose-phosphate synthase is involved in sucrose synthesis, while sucrose synthase and invertase are mainly responsible for sucrose break-down [16, 17]. Sucrose is converted into UDPG and fructose under the role of sucrose synthase, which is the first step in the conversion of sucrose to starch $[5,9,10]$. Furthermore, sucrose synthase is also capable of catalyzing sucrose synthesis in a reversible manner.

It is commonly believed that invertase and sucrose synthase participate in the transfer of sucrose to the sink organs, and both of them have been verified to be closely related to the phloem unloading processes [18, 19]. In recent years, studies paid more attention to regulation of the expression patterns of Sus genes and enzymology properties of Sus protein, and the activity of Sus have been found to be related to the sink strength in tomato and sweet potato $[20,21]$. Usuda et al. found that the sink strength has a strong relationship with the activity of sucrose synthase instead of the activity of invertase [22]. Moreover, the Sus genes reported in various plants have been demonstrated to play critical roles in regulation of carbon partitioning, which is responsible for metabolic structure and storage functions of the plant cell [23]. For instance, the validity of Sus cleavage has been verified to be tightly linked with sink strength of different starch storing organs, such as carrot roots, potato tubers, pea embryos and maize kernels [5, 2427].

Carrot (Daucus carota L.), a biennial dicot species of genus Daucus (Apiaceae), is widely cultivated as root vegetable all over the world. With its great nutrition and economic value, carrot has been well known as a perfect model plant for genetic and molecular studies [28, 29]. As one of the major sink organs, the growth and development of carrot root requires an increasingly sink activity, which is acquired by activating sucrose metabolism.

To better improve the edible quality of carrot, it is essential to figure out the sucrose metabolism mechanism.
In this study, we sampled root materials at five developmental stages from one wild and three cultivated accessions. 'Songzi' is a wild type harboring white and lignified root, which was preserved in the National Mid-term Genebank of Vegetable Genetic Resources, Chinese Academy of Agricultural Sciences [30]. For the other three cultivated types, 'Kurodagosun' is the most common carrot cultivar with orange and fleshy root, 'Baiyu' is a nutrientrich cultivar with white and fleshy root, and 'Zizhou' is a purple carrot cultivar rich in anthocyanins and carotene. The changes in soluble sugar content and sucrose content of four kinds of carrots over the period of root growth were surveyed. The expression of genes involved in sucrose metabolism was also determined by qPCR. The results from our study may provide abundant information for plant breeding and aid in the improvement of carrot nutrition and quality.

\section{Results}

Growth analysis of carrot plants at various developmental stages

Carrot roots, petioles, and leaf blades from 30-, 45-, 60-, 75-, and 90 DAS were sampled (Fig. 1). At about 45 DAS, a splash of orange firstly appeared on the root surface of 'Kurodagosun', which was maintained in the following development process. Carrot root was consistently purple in color in 'Zizhou' after 45 DAS. By contrast, the root color of 'Baiyu' was always white during root development. Both 'Baiyu' and 'Songzi' had a lignified root, but the degree of lignification of 'Baiyu' was lower than that of 'Songzi'.

Root development was evaluated by measuring the shoot and root fresh weights (Fig. 2). On the whole, before $45 \mathrm{DAS}$, the root weight was less than the shoot weight, whereas an opposite trend was shown after then. Both root weight and diameter increased significantly between 45 and 60 DAS, as well as the root-shoot ratio(R/S). After 60 DAS, all cultivars showed a moderate increase in root and shoot weight (Fig. 2).

\section{Cloning and phylogenetic analysis of genes encoding Sus in carrot}

Three genes (DcSus1, DcSus2, and DcSus3) encoding Sus were identified and cloned in carrot roots based on the carrot genomic and transcriptomic database [31]. The primers used for cloning genes were shown in Table 1 and the results were summarized in Additional files 1, 2, and 3. The length of DcSus1, DcSus2, and DcSus3 were $2427 \mathrm{bp}, 2454 \mathrm{bp}$ and $2628 \mathrm{bp}$, encoding 808, 817 and 885 amino acids, respectively. To further study DcSus in carrot and investigate the relationship of Sus between plant species, the multiple amino acid alignment of 58 sequences from NCBI database (Additional file 4) and 3 DcSus genes were used to construct phylogenetic tree 

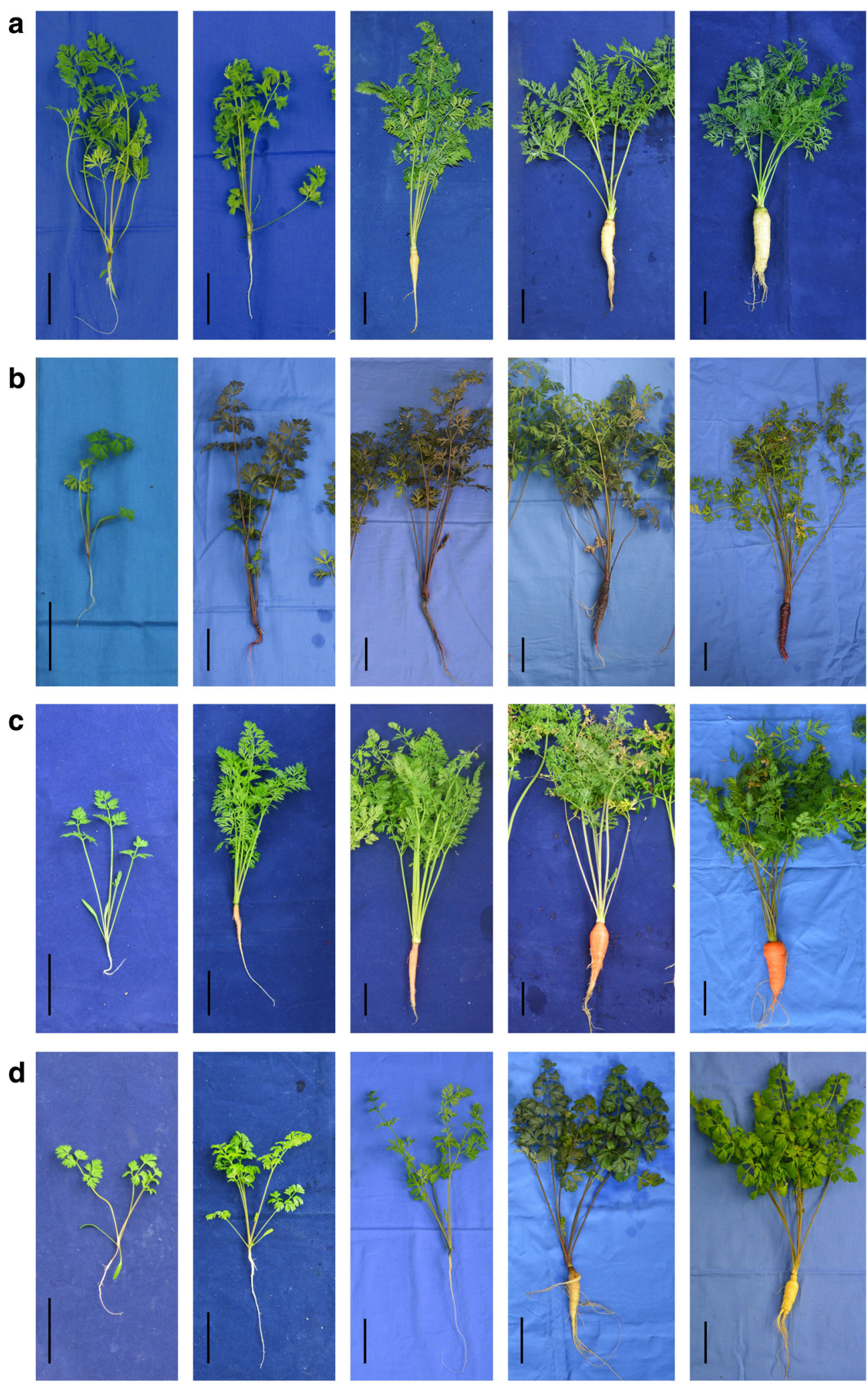

Fig. 1 Growth status of four carrot cultivars at five developmental stages. The carrot cultivars used in this study include 'Baiyu' (a), 'Zizhou' (b),

'Kurodagosun' (c), and 'Songzi' (d). The five developmental stages were stage 1 (30 DAS), stage 2 (45 DAS) stage 3 (60 DAS), stage 4 (75 DAS), and stage 5 (90 DAS). Black lines at the lower left corner represent $5 \mathrm{~cm}$ 

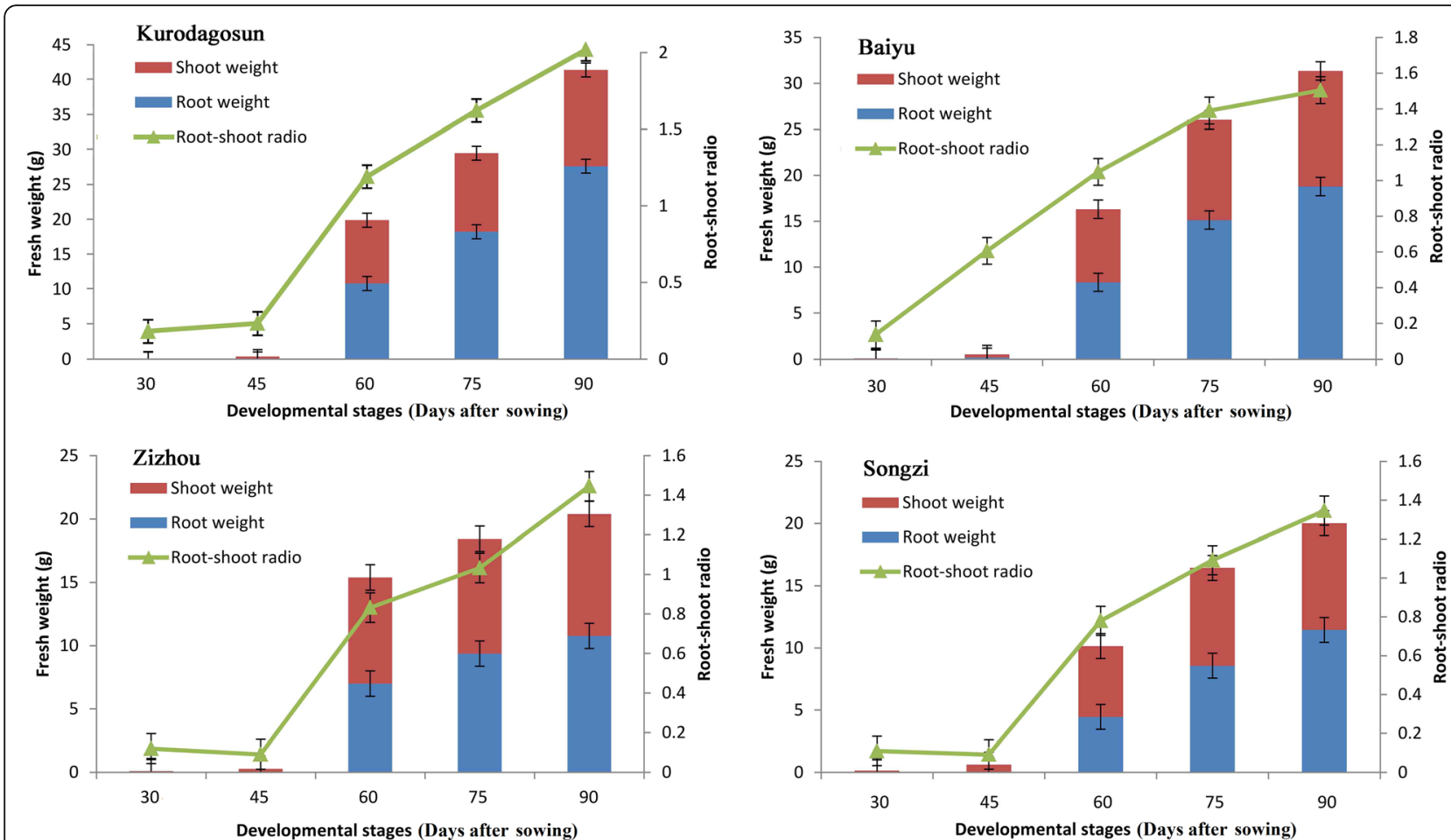

Fig. 2 Characteristics of fresh weight of root (blue columns) and shoot (red columns) and root-shoot ratio (green triangles) in carrot. The five developmental stages were stage 1 (30 DAS), stage 2 (45 DAS), stage 3 (60 DAS), stage 4 (75 DAS), and stage 5 (90 DAS). Error bars represent standard deviation among three independent replicates. Data are means of three replicates \pm SD

(Fig. 3). With two bacterial Sus used as out-groups, 58 plant Sus genes were classified into three major groups, named Sus I, II and III. As expected, DcSus1, DcSus2 and DcSus3 fall into Sus I, II and III group, respectively. Sus genes from dicots and monocots are found in all the three groups, indicating their evolutionary divergence before the separation of dicots and monocots. In contrast to groups Sus II and III, group Sus I could be further divided into two distinct sub-groups, containing one monocot group and one dicot group.

\section{Changes of soluble sugar content, sucrose content and sucrose synthase (Sus) activity during root development}

To compare the difference in sugar accumulation among the four carrot cultivars, carrot roots at different developmental stages were harvested. The soluble sugar contents were measured at five successive developmental stages (Fig. 4a). Soluble sugar content in 'Baiyu', 'Songzi', and 'Zizhou' roots showed an increasing trend during carrot root development. The soluble sugar content in 'Kurodagosun' increased at the first four stages, whereas a decline was detected at the last stage. The soluble sugar content of 'Zizhou' was the highest among the four carrot cultivars before 45 DAS, but was surpassed by 'Kurodagosun' after then. For the two cultivars with lignified roots, 'Baiyu' and 'Songzi', the soluble sugar content of the former was always lower than that of the latter (Fig. 4a). On the other hand, the concentration of sucrose increased gradually from 30 DAS to 90 DAS (Fig. 4b). DcSus activity was less in high sucrose accumulating cultivars ('Kurodagosun', 'Songzi') than in low sucrose accumulating cultivars ('Baiyu', 'Zizhou'). DcSus activity was higher in immature taproots than that in mature taproots in all cultivars. However, the enzymatic activity of sucrose synthases in taproots showed decreasing trends at five developmental stages in four carrot cultivars (Fig. 5). The correlations of DcSus activity with sucrose content and soluble sugar content are depicted in Fig. 6. The DcSus activity showed negative correlation with soluble sugar content $(p<0.05 ; r=-0.538)$ and strong negative correlation with sucrose concentration $(p<0.01 ; r=-0.628)$ (Table 2$)$.

\section{Expression profiles of genes encoding DcSus in carrot}

qPCR was conducted to detect the relative expression levels of three DcSus genes (DcSus1, DcSus2, and DcSus3) at five developmental stages among the four carrot cultivars (Fig. 7). The expression patterns were also compared and plotted in the heat map (Fig. 8). The genes were down-regulated during root growth, which were negatively correlated with sucrose concentration as investigated in the present work. On the contrary, most 


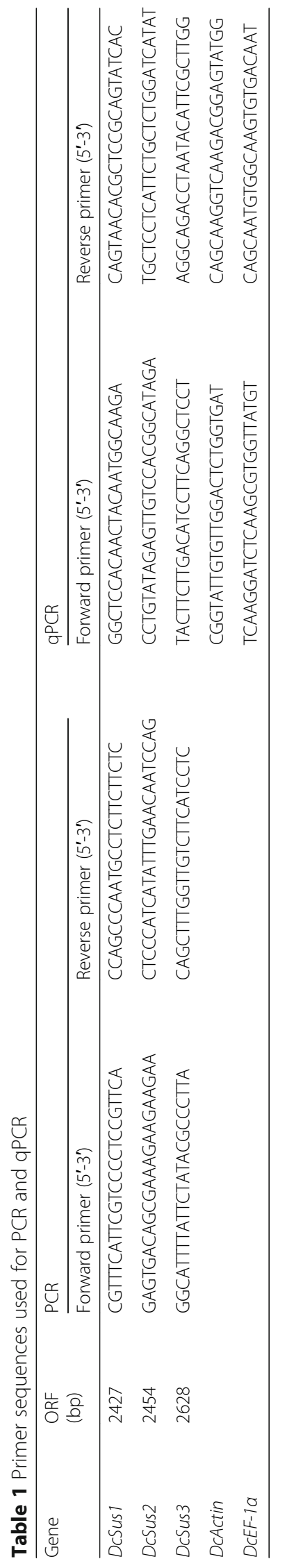




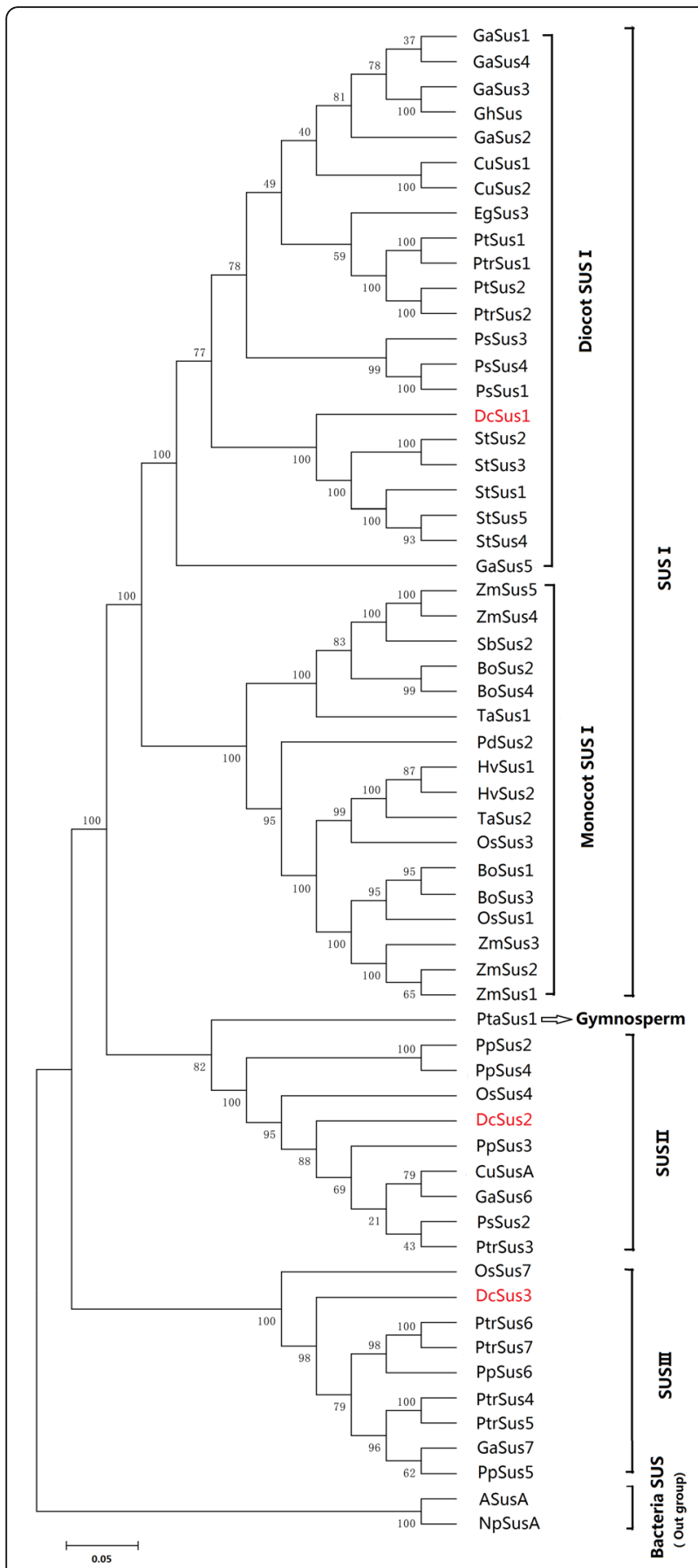

Fig. 3 Phylogenetic tree of Sus from carrot and other plant species. Unrooted phylogenetic tree of plant Sus proteins constructed using the neighbor-joining method with the MEGA 6.0 program. The accession numbers of Sus genes and their corresponding plant species are listed in Additional file 4

of the DcSus genes were up-regulated during the development of leaf blade and petiole. Among the three DcSus genes, the expression profile of DcSus1 was the highest, whereas relative transcript level of DcSus2 was the lowest (Fig. 7). The expression profiles of DcSus genes were significantly different in different carrot tissues (root, leaf blade, and petiole). Transcript levels of DcSus1 genes were highest in the petiole, while DcSus2 and DcSus3 had the highest level of expression in the leaf blade. The DcSus genes were down-regulated throughout the entire process of carrot taproot development, whereas opposite trends were demonstrated in the leaf blade and petiole (Figs. 7 and 8). Correlation analysis were conducted between $\mathrm{DcSus}$ expression profiles and sucrose and soluble sugar content, the results showed that DcSus1-3 expression profiles exhibited significant negative correlation with sucrose content $(p<$ $0.01 ; r=-.688,-.629,-.675$, respectively) and soluble sugar content $(p<0.01 ; r=-0.669,-0.572,-0.622$, respectively) (Table 3 ).

\section{Discussion}

Sucrose biosynthesis and degradation has attracted increasing attention from biologists over the past decades. Plentiful studies have recognized sucrose as a vital metabolite and signaling molecule in response to plant growth and development. Much information on sucrose metabolism has been achieved in plants, such as maize, radish, and sweet potato [21, 32,33]. However, despite its great economic and nutritional value, very little is known about the sucrose metabolism in carrot.

Accurately identifying and subsequently characterizing the genes involved in sucrose metabolism is a key step towards clarifying their physiological function and metabolic mechanism of different development processes [34]. Recent findings have indicated that most plant species had at least three Sus genes encoding Sus [35]. In maize, apart from two tissue-specific Sus genes, Sus1 and Sh1, a third Sus gene, Sus3, which is more similar to dicot than to monocot, has been reported [36]. Sus1 has a dominant role in starch synthesis and is widely expressed in almost all tissues, while Sh1 plays a major role in cell wall synthesis and is most highly expressed during the development of endosperm [37]. Till now, to our knowledge, only two genes encoding sucrose synthase had been identified in carrot [38]. Our present work through database searching and molecular cloning indicated carrot Sus gene family harbored at least three genes (DcSus1, DcSus2, and DcSus3). Similar to sucrose synthase (Sus) genes showing tissue specificity in maize, those from rice, Lotus japonicus and citrus have been proved to be expressed in stage-dependent and tissuespecific patterns $[39,40]$. The same patterns were also found in carrot of this study.

Soluble sugar content showed a continuous increase during five developmental stages in carrot. And the soluble sugar contents among the four carrot cultivars showed significantly difference. We also observed that the sugar levels in different colored carrots are as 

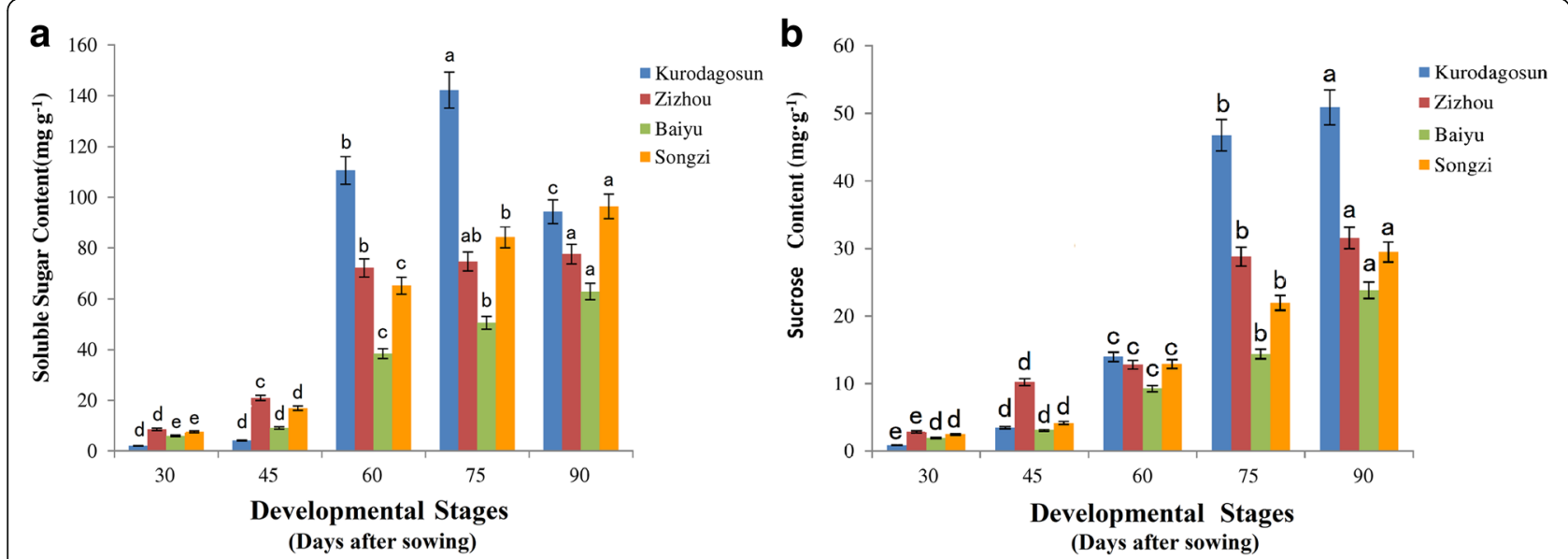

Fig. 4 Determination of soluble sugar level and sucrose content in four carrot cultivars at five developmental stages. The soluble sugar content was shown in (a) and sucrose content was shown in (b). The five developmental stages were stage 1 (30 DAS), stage 2 (45 DAS), stage 3 (60 DAS), stage 4 (75 DAS), and stage 5 (90 DAS). Error bars represent standard deviation among three independent replicates. Data are means of three replicates $\pm \mathrm{SD}$. Different lowercase letters indicate significant differences at $P<0.05$

follows: orange $>$ white $>$ purple, which is consistent with the conclusions from a previous study [41]. Sucrose content had the same variation trends comparing to soluble sugar content. Although Sus can also synthesize sucrose, the degradation reaction dominates in vivo [42, 43]. Sus activity was found to be negatively correlated with sucrose concentration in both high and low sucrose cultivars. The finding was corresponding to Lingle et al.'s research [44]. It is possible that carrot taproot obtain energy via utilizing sucrose as a carbon source and depends on it cleavage into hexose sugars [38].

In the present study, we identified three genes encoding sucrose synthase and demonstrated that DcSus1 had the highest transcript level and was most abundantly expressed in all the tissues. Although soluble sugar content showed a sustainable growth, the expression levels of DcSus genes showed a continuous decline, which

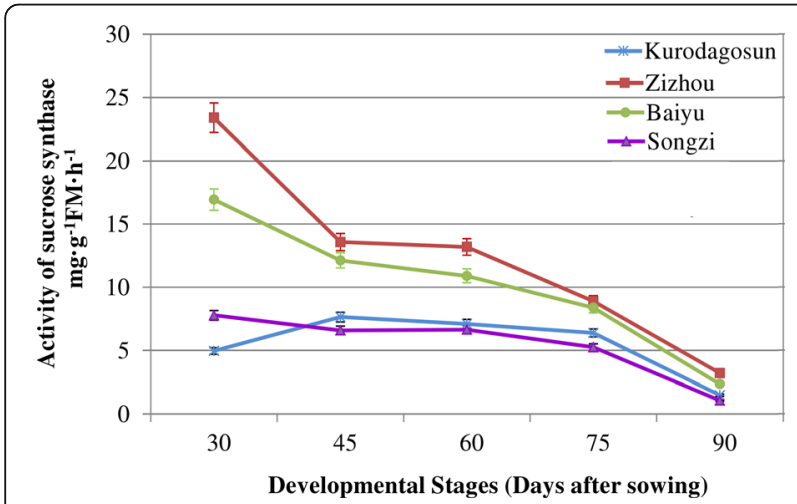

Fig. 5 Changes in the activities of DcSus enzymes in carrot during taproot development. Error bars represent standard deviation among three independent replicates. Data are means of three replicates \pm SD were negatively correlated with sucrose accumulation. Similar results were also observed in switch grass, of which, PvSUS1 was expressed ubiquitously in all the tissues and the soluble sugar content was decreased in PvSUS1-overexpressing transgenic plants [45]. The results suggested sucrose synthase may play significant roles in sucrose degradation in carrot.

\section{Conclusions}

The objective of the present study was to examine the relation among sucrose content,enzyme activities and transcript expression of the key enzymes DcSus. In this study, soluble sugar contents of four different cultivated and wild type carrots at five development stages were measured. Soluble sugar content and sucrose concentration showed increasing trends during root development, which may be influenced by the down-regulation of DcSus genes involved in sucrose metabolism. DcSus activity was higher in immature taproots than in mature taproots in all cultivars, and the transcript expression of DcSus showed a similar pattern. These results will provide useful sources for regulation of sucrose metabolism in carrot.

\section{Methods}

Plant material and growth conditions

The carrot roots used in this study were obtained from four carrot cultivars ('Kurodagosun', 'Baiyu', 'Songzi', 'Zizhou') cultivated in a climate chamber of State Key Laboratory of Crop Genetics and Germplasm Enhancement, Nanjing Agricultural University $\left(32^{\circ} 04^{\prime} \mathrm{N}, 118^{\circ} 85^{\prime} \mathrm{E}\right)$. Carrot seedlings were cultivated in flower-pots filled with 1:1 mixture of organic soil and vermiculite. The growth conditions were maintained at light (14 h light/10 h dark) and temperate 

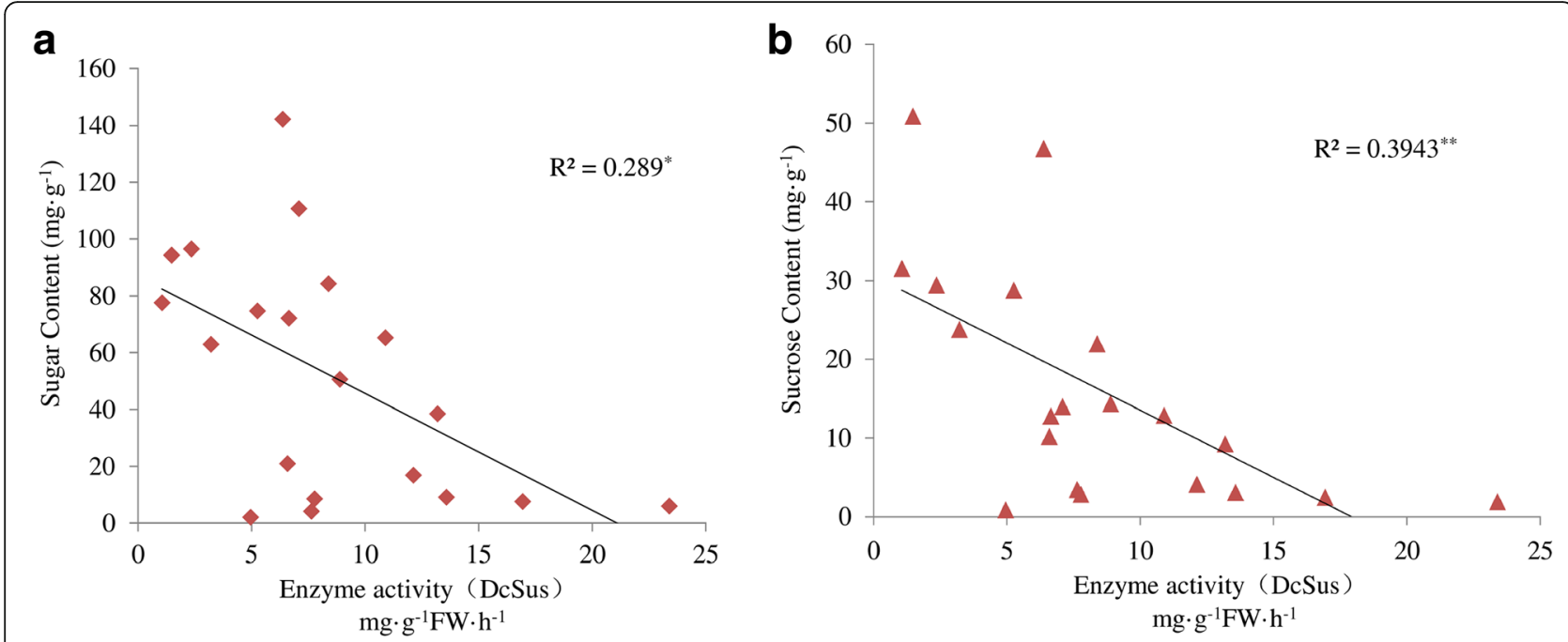

Fig. 6 Correlations between specific activities of enzymes DcSus and sucrose concentration and soluble sugar content at different physiological stages of carrot taproot development. $R^{2}$ : Coefficient of determination. a Relationship between DcSus enzyme activity and soluble sugar content. b Relationship between DcSus enzyme activity and sucrose concentration

(25 ${ }^{\circ} \mathrm{C}$ light $/ 18{ }^{\circ} \mathrm{C}$ dark) with 60 to $70 \%$ relative humidity and $240 \mu \mathrm{mol} \mathrm{m}{ }^{-2} \mathrm{~s}^{-1}$ light intensity. Carrot tissues (roots, petioles, and leaf blades) were harvested at 30, 45, 60, 75, and 90 days after sowing (DAS) and were frozen immediately in liquid nitrogen and stored at $-80{ }^{\circ} \mathrm{C}$ until RNA was extracted.

\section{RNA preparation and cDNA synthesis}

Total RNA was isolated from frozen tissues (carrot root, leaf blade and petiole) using an RNA extraction kit (Tiangen, Beijing, China) according to the manufacturer's protocol. The quantity and quality of total RNA samples were examined by a Nanodrop ND1000 spectrophotometer (Nanodrop Technologies Inc., Delaware, USA). The integrity of the isolated total RNA was checked using agarose gel electrophoresis (Additional file 5), and genomic DNA was removed using a RT reagent Kit with gDNA Eraser (Perfect Real Time) (TaKaRa, Dalian, China). The cDNA was synthesized from $500 \mathrm{ng}$ of RNA using the PrimeScript RT reagent kit (TaKaRa, Dalian, China) following the manufacturer's instructions.
Gene cloning, sequencing and phylogenetic analysis Genes encoding sucrose synthase of carrot were identified from the carrot genomic and transcriptomic database [31]. Genes were cloned by PCR amplification, which was performed with the following procedures: $94{ }^{\circ} \mathrm{C}$ for $5 \mathrm{~min}$; followed by 35 cycles of $94{ }^{\circ} \mathrm{C}$ for $30 \mathrm{~s}, 54{ }^{\circ} \mathrm{C}$ for $30 \mathrm{~s}, 72{ }^{\circ} \mathrm{C}$ for $2 \mathrm{~min} ; 7{ }^{\circ} \mathrm{C}$ for $10 \mathrm{~min}$. The amplified fragments were inserted into the pMD19-T simple vector (Takara, Dalian, China), and then transformed into the Escherichia coli strain (DH5 $\alpha)$. The plasmid DNA was sequenced by GenScript Inc. (Nanjing, China). The primers used for PCR amplification are listed in Table 1 and the sequences of the 3 genes encoding sucrose synthase in carrot were shown in Additional files 1-3.

To further investigate the DcSus from carrot, sequence searches were performed using the known DcSus (GenBank No. XM_017367066) as a query to identify homologs of other plants by NCBI blast analysis (https:// blast.ncbi.nlm.nih.gov/Blast.cgi). We used MEGA 6.0 software (http://www.megasoftware.net/) to build the neighbor-joining tree from the sequence alignment using following parameters: $\mathrm{p}$-distance model, pairwise gap deletion and 1000 bootstraps. Gene or protein accession

Table 2 Correlations between DcSus activity and soluble sugar content and sucrose content

\begin{tabular}{lllll}
\hline & Enzyme activity & Sucrose content & Enzyme activity & $\begin{array}{c}\text { Soluble sugar } \\
\text { content }\end{array}$ \\
\hline Correlation Coefficient & 1 & $-.628^{* *}$ & 1 & $-.538^{*}$ \\
Sig.(2-tailed) & & .003 & 568.037 & .014 \\
Square and cross product & 568.037 & -969.924 & 29.897 & -2336.673 \\
Covariance & 29.897 & -51.049 & -122.983 \\
\hline
\end{tabular}

Correlations were determined by Pearson correlation coefficient $(r)$ analysis. ${ }^{*}$ indicates significance at $p<0.05$ and ${ }^{* *}$ indicates significance at $p<0.01$, respectively 

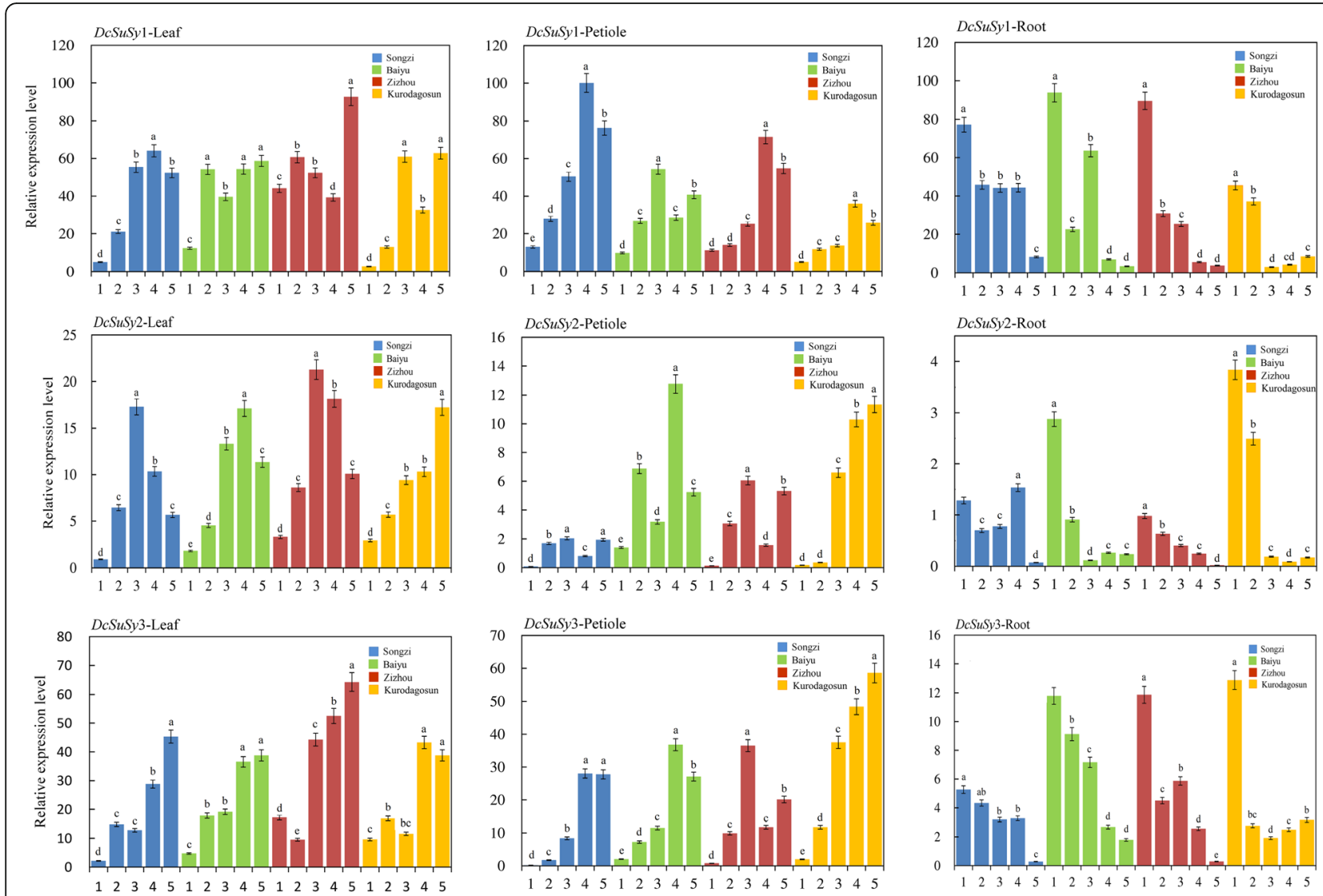

Fig. 7 Expression profiles of genes encoding Sus in four kinds of carrots at five developmental stages.The five developmental stages were stage 1 (30 DAS), stage 2 (45 DAS), stage 3 (60 DAS), stage 4 (75 DAS), and stage 5 (90 DAS). Error bars represent standard deviation among three independent replicates. Data indicate mean \pm SD of three replicates

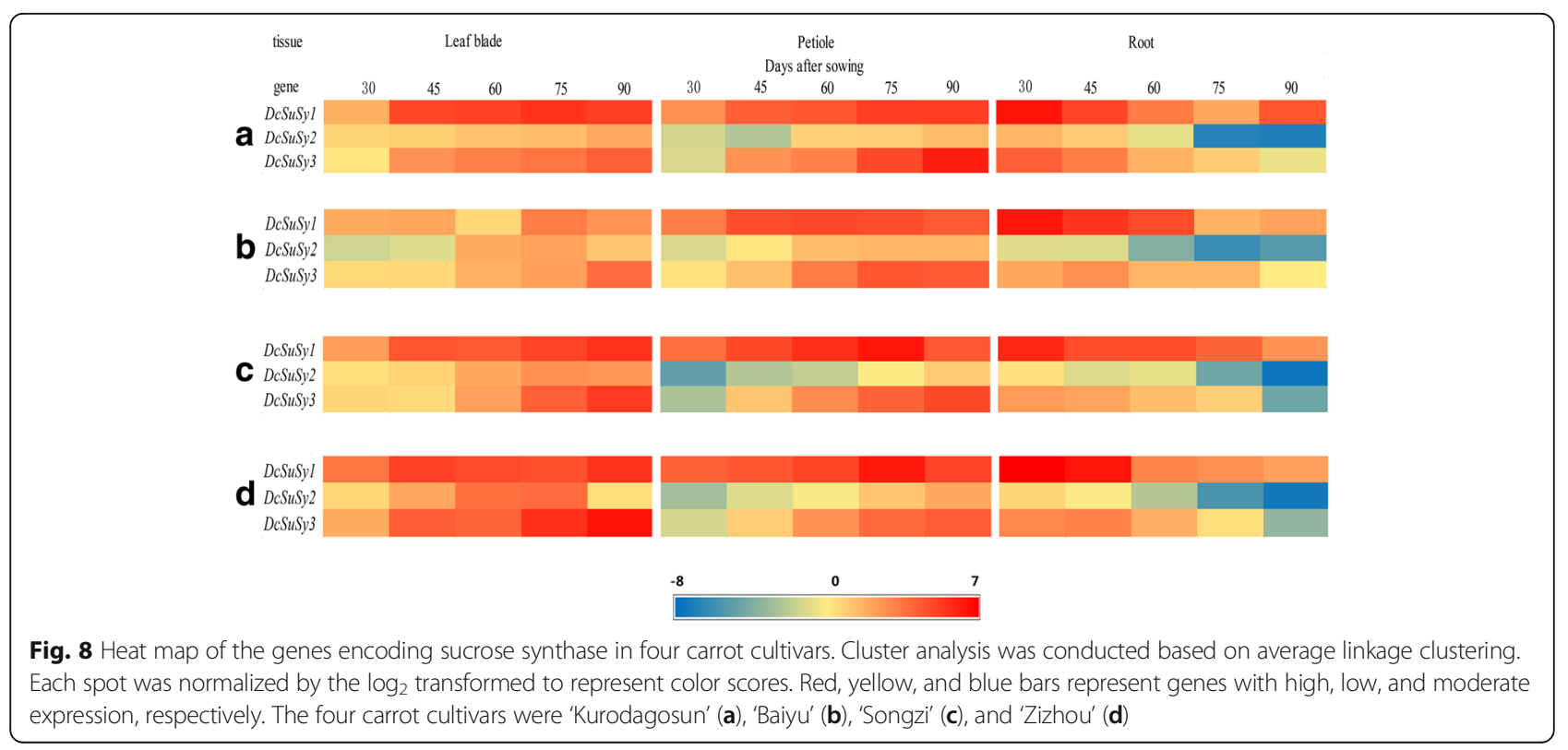


Table 3 Correlations between the genes of DcSus expression levels and sucrose content and soluble sugar content

\begin{tabular}{lllll}
\hline & Sucrose content & DcSus1 expression level & DcSus2 expression level & DcSus3 expression level \\
\hline Correlation Coefficient & 1 & $-.688^{* *}$ & $-.629^{* *}$ & $-.675^{* *}$ \\
Sig.(2-tailed) & & .001 & .003 & .001 \\
& Soluble sugar content & DcSus1 expression level & DcSus2 expression level & DcSus3 expression level \\
Correlation Coefficient & 1 & $-.669^{* *}$ & $-.572^{* *}$ & $-.622^{* *}$ \\
Sig.(2-tailed) & & .001 & 0.008 & .003 \\
\hline
\end{tabular}

Correlations were determined by Pearson correlation coefficient $(r)$ analysis. ${ }^{*}$ indicates significance at $p<0.05$ and ${ }^{* *}$ indicates significance at $p<0.01$, respectively

numbers of Sus from other plants used in this study are listed in Additional file 4.

\section{Determination of soluble sugar content and sucrose content}

Soluble sugar was purified and measured by the anthrone colorimetric method [46]. In detail, approximately $1 \mathrm{~g}$ root tissues were firstly cut into small pieces and ground in a mortar with liquid nitrogen. Then $10 \mathrm{~mL}$ of distilled water was pipetted into the sample and incubation with boiling water for $60 \mathrm{~min}$. Subsequently, the supernatant gathered by centrifugation at $12,000 \times g$ for $20 \mathrm{~min}$ at $4{ }^{\circ} \mathrm{C}$ was diluted to $25 \mathrm{~mL}$ with distilled water. Then, $0.5 \mathrm{~mL}$ of mixture was collected and added with $1.5 \mathrm{~mL}$ of distilled water, $0.5 \mathrm{ml}$ of anthrone ethyl acetate reagent, and $5 \mathrm{~mL}$ of concentrated sulfuric acid. After cooling, absorbance was measured at $620 \mathrm{~nm}$. We used a mix of $5 \mathrm{~mL}$ of concentrated sulfuric acid and $0.5 \mathrm{~mL}$ of anthrone ethyl acetate reagent as blank control. Finally, sucrose calibration curves were constructed for accurate quantification.

Sucrose was determined by the anthrone method [47]: $70 \mu \mathrm{L}$ of reaction solution was added to $70 \mu \mathrm{L}$ of $30 \%$ $\mathrm{KOH}$, boiled for $10 \mathrm{~min}$, and cooled to room temperature; $1 \mathrm{~m} \mathrm{~L}$ anthrone reagent $(0.15 \mathrm{~g}$ anthrone in $100 \mathrm{ml} \mathrm{76 \%} \mathrm{[v/v]} \mathrm{sulfuric} \mathrm{acid)} \mathrm{was} \mathrm{added} \mathrm{and} \mathrm{the} \mathrm{re-}$ action was incubated at $37{ }^{\circ} \mathrm{C}$ for $20 \mathrm{~min}$. A650 was measured immediately. The experiments were repeated with three independent samples.

\section{Extraction and assay of enzymes}

Enzymes activity of DcSus was determined from carrot roots. Freeze-dried materials (1 g) were homogenized in $100 \mathrm{mM} \mathrm{HEPES} / \mathrm{KOH}(\mathrm{pH}$ 7.5) that contained $5 \mathrm{mM} \mathrm{MgCl}_{2}, 1 \mathrm{mM}$ EDTA, $0.1 \% \beta$-mercaptoethanol and $0.1 \%$ Triton $\mathrm{X}-100$. The homogenate was centrifuged at $18,000 \mathrm{rpm}$ for $20 \mathrm{~min}$ at $4{ }^{\circ} \mathrm{C}$, and the supernatant was desalted on a HiTrap desalting column (GE Healthcare Life Sciences, Beijing, China).

\section{Assay of sucrose synthase (Sus)}

Sucrose synthase in cleavage direction was measured as the formation of UDPGIc according to Zrenner et al.
[48], with slight modifications: The assay mixture contained $20 \mathrm{mM}$ HEPES/KOH (pH 7.5), $100 \mathrm{mM}$ sucrose, $4 \mathrm{mM}$ UDP and $5 \mathrm{mM}$ DTT. $50 \mu \mathrm{L}$ of the desalted homogenate was added to $50 \mu \mathrm{L}$ of the mixture. The reaction proceeded for $20 \mathrm{~min}$ at $34^{\circ} \mathrm{C}$, and was stopped by boiling for $10 \mathrm{~min}$. UDPGIc produced was measured in a subsequent reaction in a $1 \mathrm{ml}$ volume containing $200 \mathrm{mM}$ glycine/ $\mathrm{HCl}(\mathrm{pH} 8.5), 5 \mathrm{mM} \mathrm{MgCl}_{2}$, $2 \mathrm{mM} \mathrm{NAD}^{+}$and $0.02 \mathrm{U} / \mathrm{mL}$ UDP-glucose pyrophosphorylase. Absorbance was measured at $340 \mathrm{~nm}$. Control assays were performed without sucrose and without UDP.

\section{Gene expression analysis by qPCR}

Total RNA $(1 \mu \mathrm{g})$ from each sample of different treatments was reverse transcribed using the PrimeScript 1st Strand cDNA Synthesis Kit (TaKaRa, Dalian, China). Primers used for qPCR were designed with Primer Premier 6 software (Table 1) spanning at least one intron, and a melting curve was performed to verify the specificity of primer amplification (Additional file 6). To determine the amplification efficiency for each primer set, the calibration curve for each gene was obtained by performing real-time PCR with four dilutions of cDNA $\left(10 \times, 10^{2} \times, 10^{3} \times, 10^{4} \times\right)$ (Additional file 7). Using BioRad IQ5 real-time PCR System (Bio-Rad, CA, USA), qPCR was conducted with SYBR Premix Ex Taq (TaKaRa, Dalian, China). Each reaction contained $2 \mu \mathrm{L}$ of $10 \times$ diluted cDNA strand, $10 \mu \mathrm{L}$ of SYBR Premix Ex Taq, 7.2 $\mu \mathrm{L}$ of deionized water, and $0.4 \mu \mathrm{L}$ of each primer $(20 \mathrm{mM})$, accumulating a final volume of $20 \mu \mathrm{L}$. PCR was strictly performed according to the following standards: $95{ }^{\circ} \mathrm{C}$ for $30 \mathrm{~s}$, followed by 40 cycles of $95{ }^{\circ} \mathrm{C}$ for $5 \mathrm{~s}$ and $60{ }^{\circ} \mathrm{C}$ for $30 \mathrm{~s}$. The specificity of the individual PCR amplification was checked using a heat dissociation protocol from 65 to $95{ }^{\circ} \mathrm{C}$ following the final cycle of the PCR. The results were normalized against the carrot reference genes, DcActin and DcEF1- $\alpha$, which were verified to exhibit stable levels of expression in a broad range of carrot tissues [49]. Relative gene expression level was calculated by the $2^{-\Delta \Delta C T}$ method [50]. Analysis was conducted on the data from three independent reactions (technical replicates) using samples from three biological replicates. The data used in this manuscript 
mainly came from our group's previous RNA-seq transcriptomic database [31, 51-53].

\section{Statistical analysis}

Statistical analysis was performed using One-way ANOVA on SPSS Version 20.0, followed by Duncan's multiple range test. Significant differences were set at $P<0.05$ for all analyses. Correlation between enzyme activity and sucrose content and soluble sugar content, DcSus expressions levels and sucrose content and soluble sugar content were analyzed using Pearson correlation coefficient $(r)$ at significance levels $p<0.01$ and $p<0.05$.

\section{Additional files}

Additional file 1: Figure S1. Nucleotide acid and deduced amino acid sequences of DcSus1 from carrot (DOC $33 \mathrm{~kb}$ )

Additional file 2: Figure S2. Nucleotide acid and deduced amino acid sequences of DcSus2 from carrot (DOC $33 \mathrm{~kb}$ )

Additional file 3: Figure S3. Nucleotide acid and deduced amino acid sequences of DcSus3 from carrot (DOC $34 \mathrm{~kb}$ )

Additional file 4: Table S1 List of sucrose synthase gene sequences used in this study. (DOC $37 \mathrm{~kb}$ )

Additional file 5: Figure S4. Results of RNA Electrophoresis. DC27 represents 'Kurodagosun'; BY represents 'Baiyu'; DC25 represents 'Zizhou'; SZ represents 'Songzi'. (DOC 379 kb)

Additional file 6: Figure S5. Melting curves of DcSus genes related encoding sucrose synthase and two reference genes using in $\mathrm{QPCR}$. (DOC $188 \mathrm{~kb}$ )

Additional file 7: Figure S6. Standard curves for DcEF1-a, DcActin, DcSus1, DcSus2 and DcSus3. The linear correlation (R2) and PCR efficiencies $(\% E=(10[-1 /$ slope $]-1) \times 100 \%)$ were calculated from the standard curve. (DOC $1194 \mathrm{~kb}$ )

\section{Abbreviations}

DAS: Days after sowing; Inv: Beta-fructofuranosidase; qPCR: Quantitative realtime polymerase chain reaction; SPS: Sucrose-phosphate synthase; Sus: Sucrose synthase

\section{Acknowledgements}

Not applicable.

\section{Funding}

The research was supported by the Shanxi Province Coal Based Key Scientific and Technological Project (FT201402-07); Jiangsu Natural Science Foundation (BK20130027); New Century Excellent Talents in University (NCET-11-0670); Priority Academic Program Development of Jiangsu Higher Education Institutions (PAPD).

\section{Availability of data and materials}

The datasets supporting the conclusions of this article are included within the article and its additional files. The transcriptomic database for carrot could download from NCBI under the accession number SRR2177455, and the genomic and transcriptomic data will be shared on reasonable request of the corresponding author.

\section{Consent to publish}

Not applicable.

\section{Authors' contributions}

ASX and YJL initiated and designed the research, YJL performed the experiments, YJL, GLW, JM, ZSX, FW and ASX analyzed the data, YJL wrote the paper. ASX GLW and YJL revised the paper. All authors read and approved the final manuscript.
Ethics approval and consent to participate

Not applicable.

\section{Competing interests}

The authors declare that there are no competing interests.

\section{Publisher's Note}

Springer Nature remains neutral with regard to jurisdictional claims in published maps and institutional affiliations.

Received: 16 August 2017 Accepted: 21 December 2017 Published online: 05 January 2018

References

1. Farrar J, Pollock C, Gallagher J. Sucrose and the integration of metabolism in vascular plants. Plant Sci. 2000;154(1):1-11.

2. Yang L, Xu M, Yeonjong K, He J, Scott PR. Sugar promotes vegetative phase change in Arabidopsis thaliana by repressing the expression of MIR156A and MIR156C. elife. 2013:2:e00260.

3. Stokes ME, Campbell MM. Interplay between sucrose and folate modulates auxin signaling in Arabidopsis. Plant Physiol. 2013;162(3):1552-65.

4. Xiong Y, Mccormack M, Li L, Hall Q, Xiang C, Sheen J. Glucose-TOR signalling reprograms the transcriptome and activates meristems. Nature. 2013:496:181-6.

5. Chourey PS, Taliercio EW, Carlson SJ, Ruan YL. Genetic evidence that the two isozymes of sucrose synthase present in developing maize endosperm are critical, one for cell wall integrity and the other for starch biosynthesis. Mol Gen Genet. 1998;259(1):88-96.

6. Heim U, Weber H, Bäumlein H, Wobus U. A sucrose-synthase gene of ViciafabaL.: expression pattern in developing seeds in relation to starch synthesis and metabolic regulation. Planta. 1993;191(3):394-401.

7. Muñoz FJ, Baroja-Fernández E, Morán-Zorzano MT, Viale AM, Etxeberria E, Alonsocasajús N, et al. Sucrose synthase controls both intracellular ADP glucose levels and transitory starch biosynthesis in source leave. Plant Cell Physiol. 2005;46(8):1366-76.

8. Chen YC, Chourey PS. Spatial and temporal expression of the two sucrose synthase genes in maize: immunohistological evidence. Theor Appl Genet. 1989:78(78):553-9.

9. Barojafernández E, Muñoz FJ, Montero M, Etxeberria E, Sesma MT, Ovecka $\mathrm{M}$, et al. Enhancing sucrose synthase activity in transgenic potato (Solanum tuberosum L.) tubers results in increased levels of starch, ADP glucose and UDP glucose and total yield. Plant Cell Physiol. 2009;50(9):1651-62.

10. Yang J, Zhang J. Activities of key enzymes in sucrose-to-starch conversion in wheat grains subjected to water deficit during grain filling. Plant Physiol. 2004;135(3):1621-9.

11. Albrecht $G$, Mustroph A. Sucrose utilization via invertase and sucrose synthase with respect to accumulation of cellulose and callose synthesis in wheat roots under oxygen deficiency. Russ J Plant Phys. 2003;50(6):813-20.

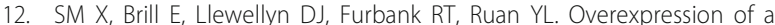
potato sucrose synthase gene in cotton accelerates leaf expansion, reduces seed abortion, and enhances fiber production. Mol Plant. 2012; 5(2):430-41

13. Spyropoulos CG. Control of sucrose metabolism in polyethylene clycol stressed carob (Ceratonia siliqua L.) young seedlings. J Exp Bot. 1982;33 (137):1210-9.

14. Trouverie J, Thevenot C, Rocher JB, Sotta B, Prioul J. The role of abscisic acid in the response of a specific vacuolar invertase to water stress in the adult maize leaf. J Exp Bot. 2003:54(390):2177-86.

15. Gupta AK, Kaur N. Sugar signalling and gene expression in relation to carbohydrate metabolism under abiotic stresses in plants. J Biosci. 2006; 30(5):761-76

16. Huber SC, Huber JL. Role and regulation of sucrose-phosphate synthase in higher plants. Annu Rev Plant Physiol Plant Mol Biol. 1996;47(2):199-222.

17. Sturm A, Tang GQ. The sucrose-cleaving enzymes of plants are crucial for development, growth and carbon partitioning. Trends Plant Sci. 1999;4(10):401-7

18. Martin T, Frommer WB, Salanoubat M, Willmitzer L. Expression of an Arabidopsis sucrose synthase gene indicates a role in metabolization of sucrose both during phloem loading and in sink organs. Plant J. 1993;4(2): 367-77. 
19. Coleman HD, Yan J, Mansfield SD. Sucrose synthase affects carbon partitioning to increase cellulose production and altered cell wall ultrastructure. Proc Natl Acad Sci. 2009;106(13):118-23.

20. Wang F, Smith A. Sucrose synthase, starch accumulation, and tomato fruit sink strength. Plant Physiol. 1993;101(1):321-7.

21. Li XQ, Zhang D. Gene expression activity and pathway selection for sucrose metabolism in developing storage root of sweet potato. Plant Cell Physiol. 2003;44(6):630-6.

22. Usuda H, Demura T, Shimogawara K, Fukuda H. Development of sink capacity of the "storage root" in a radish cultivar with a high ratio of "storage root" to shoot. Plant cell physiol. 1999;40(4):369-77.

23. Haigler $\mathrm{CH}$, Ivanovadatcheva M, Hogan PS, Salnikov W, Hwang S, Martin K, et al. Carbon partitioning to cellulose synthesis. Plant Mol Biol. 2001;47:29-51.

24. Tang GQ, Sturm A. Antisense repression of sucrose synthase in carrot (Daucus carota L.) affects growth rather than sucrose partitioning. Plant Mol Biol. 1999; 41(41):465-79.

25. Zrenner R, Salanoubat M, Willmitzer L, Sonnewald U. Evidence of the crucial role of sucrose synthase for sink strength using transgenic potato plants (Solanum tuberosum L). Plant J. 1995;7(1):97-107.

26. Barratt DH, Barber L, Kruger NJ, Smith AM, Wang TL, Martin C. Multiple, distinct isoforms of sucrose synthase in pea. Plant Physiol. 2001;127(2): 655-64.

27. Fu H, Park WD. Sink- and vascular-associated sucrose synthase functions are encoded by different gene classes in potato. Plant Cell. 1995;7(9):1369-85.

28. Luby CH, Maeda HA, Goldman IL. Genetic and phenological variation of tocochromanol (vitamin E) content in wild (Daucus carota L. Var. carota) and domesticated carrot (D. carota L. Var. sativa). Hortic Res. 2014;1:14015.

29. Wang GL, Xiong F, Que F, ZS X, Wang F, Xiong AS. Morphological characteristics, anatomical structure, and gene expression: novel insights into gibberellin biosynthesis and perception during carrot growth and development. Hortic Res. 2015;2:15028.

30. Li JR, Zhuang FY, CG O, Hu H, Zhao ZW, Mao JH. Microspore embryogenesis and production of haploid and doubled haploid plants in carrot (Daucus carota L.). Plant Cell Tiss Org. 2013;112(3):275-87.

31. Xu ZS, Tan HW, Wang F, Hou XL, Xiong AS. CarrotDB: a genomic and transcriptomic database for carrot. Database J Biol Databases Curation. 2014;40(5):1-8.

32. Ren X, Zhang J. Research progresses on the key enzymes involved in sucrose metabolism in maize. Carbohydr Res. 2013;368(10):29-34.

33. Yu R, Liang X, Wei Z, Yan W, Luo X, Wang R. De novo taproot transcriptome sequencing and analysis of major genes involved in sucrose metabolism in radish (Raphanus sativus L.). Front Plant Sci. 2016;7:5-17.

34. Chen A, He S, Li F, Zhao L, Ding M, Liu Q. Analyses of the sucrose synthase gene family in cotton: structure, phylogeny and expression patterns. BMC Plant Biol. 2012;12(1):1-17.

35. Koch KE, Nolte KD, Duke ER, Mccarty DR, Avigne WT. Sugar levels modulate differential expression of maize sucrose synthase genes. Plant Cell. 1992;4(1):59-69.

36. Carlson SJ, Chourey PS, Helentjaris T, Datta R. Gene expression studies on developing kernels of maize sucrose synthase (Sus) mutants show evidence for a third Sus gene. Plant Mol Biol. 2002;49(1):15-29.

37. Hirose $T$, Scofield GN, Terao T. An expression analysis profile for the entire sucrose synthase gene family in rice. Plant Sci. 2008;174(5): 534-43.

38. Sturm A, Lienhard S, Schatt S, Hardegger M. Tissue-specific expression of two genes for sucrose synthase in carrot (Daucus carota L.). Plant Mol Biol. 1999; 39(2):349-60.

39. Wang AY, Kao MH, Yang WH, Sayion Y, Liu LF, Lee PD, et al. Differentially and developmentally regulated expression of three rice sucrose synthase genes. Plant Cell Physiol. 1999;40(8):800-7.

40. Horst I, Welham T, Kelly S, Kaneko T, Sato S, Tabata S, et al. Tilling mutants of Lotus Japonicus reveal that nitrogen assimilation and fixation can occur in the absence of nodule-enhanced sucrose synthase. Plant Physiol. 2007;144(2):806-20

41. Baranski R, Allender C, Klimek-Chodacka M. Towards better tasting and more nutritious carrots: carotenoid and soluble sugar content variation in carrot genetic resources. Food Res Int. 2012;47(2):182-7.

42. Geigenberger PSM. Sucrose synthase catalyses a readily reversible reaction in vivo in developing potato tubers and other plant tissues. Planta. 1993; 189(3):329-39.
43. Botha FC, Black KG. Sucrose phosphate synthase and sucrose synthase activity during maturation of internodal tissue in sugarcane. Aust J Plant Physiol. 2000;27(6):81-5.

44. Lingle SE, Smith RC. Sucrose metabolism related to growth and ripening in sugarcane internodes. Crop Sci. 1991;31(1):172-7.

45. Poovaiah CR, Mazarei M, Decker SR, Turner GB, Sykes RW, Davis MF, et al. Transgenic switchgrass (Panicum virgatum L.) biomass is increased by overexpression of switchgrass sucrose synthase (PVSUS1). Biotechnol J. 2015;10(4):552-63.

46. Liu HR, Song HX, Liu DP, Guan CY, Liu Q, Chen SY. Dynamics changes of soluble sugar and free amino acid contents in stem and leaf of different oilseed rape varieties. Acta Agric Boreali Occidentalis Sin. 2007;1(28):20-6.

47. Van HE. Direct microdetermination of sucrose. Anal Biochem. 1968;22(2):280-3.

48. Zrenner R, Salanoubat M, Willmitzer L, Sonnewald U. Evidence of the crucial role of sucrose synthase for sink strength using transgenic potato plants (Solanum tuberosum L.). Plant J Cell Mol Biol. 1995;7(1): 97-107.

49. Wang GL, Tian C, Jiang Q, ZS X, Wang F, Xiong AS. Comparison of nine reference genes for real-time quantitative PCR in roots and leaves during five developmental stages in carrot (Daucus carota L.). J Hortic Sci Biotechnol. 2016:91(3):264-70.

50. Pfaffl MWA. New mathematical model for relative quantification in real-time RT-PCR. Nucleic Acids Res. 2001;29(9):e45-5.

51. Wang GL, Jia XL, ZS X, Wang F, Xiong AS. Sequencing, assembly, annotation, and gene expression: novel insights into the hormonal control of carrot root development revealed by a high-throughput transcriptome. Mol Gen Genomics. 2015;290(4):1379-91.

52. Wang GL, Huang W, Li MY, Xu ZS, Wang F, Xiong AS. Expression profiles of genes involved in jasmonic acid biosynthesis and signaling during growth and development of carrot. Acta Biochim Biophys Sin. 2016:48(9):795-803.

53. Li MY, Xu ZS, Tian C, Huang Y, Wang F, Xiong AS. Genomic identification of WRKY transcription factors in carrot (Daucus carota) and analysis of evolution and homologous groups for plants. Sci Rep. 2016;6:23101. https://doi.org/10.1038/srep23101.

\section{Submit your next manuscript to BioMed Central and we will help you at every step:}

- We accept pre-submission inquiries

- Our selector tool helps you to find the most relevant journal

- We provide round the clock customer support

- Convenient online submission

- Thorough peer review

- Inclusion in PubMed and all major indexing services

- Maximum visibility for your research

Submit your manuscript at www.biomedcentral.com/submit 